\title{
Photosynthesis and Hill Reaction - a Physiological Inquiry into a Thermosensitive Genic Male Sterile (TGMS) Rice Used in Two Line Breeding
}

\author{
Vijayalakshmi D. ${ }^{*}$, Bangarusamy U. \\ Department of Crop Physiology, Tamil Nadu Agricultural University, Coimbatore- 641 003, Tamil Nadu, India \\ *Corresponding author: vijiphysiology@gmail.com
}

Copyright (C) 2014 Horizon Research Publishing All rights reserved.

\begin{abstract}
An investigation was carried out to understand the physiological mechanisms of male sterility in rice. The critical sterility temperature and critical stage of thermosensitivity of the selected TGMS (Thermosensitive Genie Male Sterile) line, TS 29 was studied using a Phytotron. Variations in the physiological traits were analyzed at Stage VII of panicle development (Filling phase of pollen, floret and panicle reach full length and colour turns to green). High significant reductions in photosynthetic rate, transpiration rate, hill reaction, sugars and carbohydrate contents were recorded. The high temperature induced male sterility in TGMS line was associated with accumulation of starch and higher diffusive resistance. However a reverse of all the above responses was found in the TS 29 grown under fertility inducing low temperature and in the variety CO 46. The results revealed that some physiological traits play an important role by acting as signals or messengers in response to temperature leading to pollen abortion.
\end{abstract}

Keywords Rice, TGMS, Photosynthesis, Hill Reaction, Starch, Carbohydrates, Sterility, Fertility

\section{Introduction}

Rice occupies a pivotal place in food and livelihood of Indian population, as it is the most important food grain in the diets of many Indians. To sustain this self-sufficiency and to meet the food requirements of the future, India has to increase production of 25 to 30 million tonnes of milled rice every year [1]. Among the various possible approaches to break yield barriers in rice, hybrid rice technology is the most promising one. Two-line system hybrid rice has been extensively studied to replace the existing three line system. Discovery of TGMS (Thermosensitive Genie Male Sterile) sources has lead to further breakthrough for commercialization of hybrid rice. Thermosensitive Genic Male Sterility (TGMS) is a type of genic male sterility expression regulated by certain temperature conditions. This male sterility system is considered more efficient than Cytoplasmic Male Sterility (CMS) system for hybrid rice breeding. Though considerable information is available on the heterosis and combining ability of two line hybrids using TGMS, the physiological basis of male sterility caused by high temperature is still to be explored. Bose and Ghosh [2] studied the high temperature effect on photosynthetic rate in rice and reported that the relative decline of the rate of whole chain electron transport and PS II activity was more pronounced. Studies on the photochemical activity of a TGMS line Nongken $58 \mathrm{~S}$ suggested a decrease in photochemical activity in Nongken $58 \mathrm{~S}$ chloroplasts during sterility [3]. So, an attempt has been made to gather information on the changes that are taking place during the fertility transformation of a stable TGMS line, TS29 in the photosynthetic rate and related gas exchange parameters and hill reaction rate, in which the isolated chloroplasts give off oxygen in the presence of unnatural reducing agents after exposure to light. It represents the efficiency of photosynthetic electron transport at PSII level. So, understanding the physiological basis like carbohydrate metabolism and starch synthesis during fertility transformation of this novel source of male sterility can be an effective genetic tool in crop improvement programmes. Though considerable information is available on the heterosis and combining ability of two line hybrids using TGMS, the physiological and biochemical basis of male sterility caused by high temperature is still to be explored.

\section{Materials and Methods}

The TS 29 line along with a known thermoinsensitive variety, $\mathrm{CO} 46$ formed the basic material for the experiment. Plants were grown in the Glasshouse in plastic pots. Sowing date was adjusted, so that, the TS 29 line and CO 46 came to panicle initiation stage during the $1^{\text {st }}$ week of December, 2012. The mean maximum and minimum temperatures for 
December and January were 28.6 and $19.9^{\circ} \mathrm{C}$ respectively. The plants were transferred to the growth chamber when they were in stage III of panicle development (The stage when the panicles were $1 \mathrm{~mm}$ long and covered with white hairs) The plants were kept inside Phytotron up to stage VII of panicle development (Filling phase of pollen, floret and panicles reach full length and colour turns to green). The gas exchange measurements were done immediately at stage VII. The temperature treatment, CST (Critical Sterility Temperature) given in the Phytotron to imitate the diurnal variation of summer season for induction of male sterility, is given in Table 1.

Table 1. Temperature Treatments Induced Inside The Phytotron

\begin{tabular}{|c|c|c|c|}
\hline Time (hrs) & $\begin{array}{c}\text { Temp } \\
\left({ }^{\circ} \mathrm{C}\right)\end{array}$ & RH (\%) & $\begin{array}{c}\text { Light intensity } \\
\left(\mu \mathrm{M} \mathrm{m}^{-2} \mathrm{~s}^{-1)}\right.\end{array}$ \\
\hline $08.00-10.00$ & $34^{\circ} \mathrm{C}$ & 80 & 600 \\
\hline $10.00-12.00$ & $35^{\circ} \mathrm{C}$ & 70 & 800 \\
\hline $12.00-16.00$ & $36^{\circ} \mathrm{C}$ & 60 & 800 \\
\hline $16.00-08.00$ & $35^{\circ} \mathrm{C}$ & 60 & 600 \\
\hline
\end{tabular}

The Statistical design was CRD with five replications, with five plants constituting each replication. In each plant two measurements were made and the mean taken. Gas exchange parameters namely, photosynthetic rate $(\mu \mathrm{mol}$ $\left.\mathrm{CO}_{2} \mathrm{~m}^{-2} \mathrm{~s}^{-1}\right)$, transpiration rate $\left(\mathrm{mmol} \mathrm{H}_{2} \mathrm{O} \mathrm{m}^{-2} \mathrm{~s}^{-1}\right)$ and diffusive resistance $\left(\mathrm{s} \mathrm{cm}^{-1}\right)$ were recorded using an advanced portable $\mathrm{CO}_{2}$ Gas Analyzer (model CI - $301 \mathrm{CID}$ Inc., Made in USA). The readings were taken during 11:00 to 12:00 noon on clear sunny days, when the PAR (Photosynthetic Active Radiation) was more than $1000 \mu$ moles $\mathrm{m}^{-2} \ell^{-1}$. Second fully opened leaf from the top was clamped to the leaf chamber and held perpendicular to the incident light and only the computed values were taken. The instrument was working in open type principle, thus maintaining a constant $\mathrm{CO}_{2}$ flux to the leaf chamber, which is at ambient concentration. $\mathrm{RH}$ was also maintained at a steady state level equal to the ambient RH to simulate a condition very similar to that of the ambient air. The Hill reaction was measured by recording the reduction of 2 , 6-Dichlorophenol indophenol (DCIP), as described by [4]. The rate of photosynthetic electron transport was expressed as micromoles of DCIP reduced per milligram chlorophyll per hour. Dry sample was used for estimation of carbohydrate fractions and reducing sugars and total sugars were estimated from the ethanol extract of leaves following the method of [5] and expressed as $\mathrm{mg} \mathrm{g}^{-1} \mathrm{FW}$. The Starch content was estimated by extracting samples in perchloric acid 52 per cent after removing sugars by repeated washing with methanol $(80 \%)$ and the content was expressed in $\mathrm{mg}$ $\mathrm{g}^{-1}$ FW [6]. Total carbohydrates were estimated using anthrone reagent [6] after hydrolyzing the leaf samples with $\mathrm{HCl}$ and expressed in $\mathrm{mg} \mathrm{g}^{-1} \mathrm{FW}$.

\section{Results and Discussion}

Photosynthetic rate apparently declined steeply in TS 29 plants subjected to CST treatment. The decline in the rate was as high as 36.1 per cent, whereas, it was only 10.4 per cent in CO 46 under CST treatment (Table.2). It is apparent that any reduction in current photosynthesis during the vulnerable panicle development stage may deprived the developing panicles from getting sufficient nourishments and weaken the pollen formation. Vani [7] observed that exposure of intact rice plants to elevated temperatures might inhibit photosynthesis at multiple sites. The reduction in photosynthetic rate in sensitive plants could be more severe when the electron transport in PS II was impaired and the important carboxylating enzyme, Rubisco might become less stable and begin to denature above the optimum temperature [8]. Roystephen [9] reported reduction in Rubisco content upto 42 per cent in sterile TGMS lines due to CST treatment. Probably, this reduction in Rubisco might be the reason for steep reduction in $\mathrm{P}_{\mathrm{n}}$ rate, as recorded in the present study. Unlike $P_{n}$, the transpiration rate (E) was not affected severely by CST treatment, as only 6.7 per cent reduction in TS 29 and 2.6 per cent reduction in $\mathrm{CO} 46$ were recorded. Even this increased reduction in the rate of TS 29 would have adversely affected the gas exchange and reduced $P_{n}$ activity. It is pertinent to note the revelation that, energy balance considerations showed an increase in plant body temperature, if the transpiration of the plant decreased that would lower the latent heat exchange [10]. As could be normally expected, diffusive resistance $\left(\mathrm{r}_{\mathrm{s}}\right)$ did increase with increase in temperature, but the increase was 14.3 per cent higher in TS 29 due to CST treatment, whereas the increase was only 3.9 per cent in CO 46 after the same treatment (Table.2). The results indicated that inspite of increased diffusive resistance as a result of elevated temperature; the thermosensitive TS 29 could produce only sterile pollens. This may be because the basic calibration and operational procedures for these instruments assume that leaf temperature (Tleaf) is the same as porometer temperature ( $\mathrm{T}$ cup) [11]. The rate of hill reaction represents the efficiency of photosynthetic electron transport at PS II level, was severely hampered by CST treatment in TS 29 (30.9 per cent reduction), as compared to CO 46 (0.8 per cent reduction). The result obviously indicated the impairment of PS II system in sensitive TS 29, which might be the major cause for reduced photosynthetic rate. Vani [7], in support of the present finding, indicated loss in PS II photochemistry and an associated loss in the number of functional PS II units in rice leaves when the temperature increased over an optimum level. A decreased photochemical activity and inefficient light energy transformations in PS II under sterility inducing conditions was observed in rice [3]. This reduced hill reaction rate might produce attendant male sterility was in consonance with the findings of $[9,12]$. Apart from that, both reducing and non-reducing sugars pool was seriously affected due to the high temperature CST treatment. The reduction in total sugars due to CST treatment was as high as 30.3 per cent, it appears that the reduction is more severe in non-reducing sugars than in reducing sugars (Table.3). Similar to reduction in sugar fractions, the CST treatment distinctly reduced the 
carbohydrate content while increased the starch content of leaves (Table 3). The reduction might be attributed to the reduced rate of current photosynthesis during panicle development. This might in turn have affected the pollen starch content thereby leading to sterility. In support of the above finding, Markova and Daskaloff [13] in pepper and Chauhan and Kinoshita [14] in sugarbeet observed decrease in reducing sugar in plants producing sterile male anthers. They attributed reduced photosynthesis and reduced supply of assimilates for the decrease in reducing sugar that culminated in male sterility. That CST treated sterile rice lines might accumulate more starch was corroborated by the findings of several authors $[15,16]$. Many reports have indicated that under stress condition, accumulation of sugars could provide osmotic effect and mitigate stress damage in plants, but this favour has been denied to TS 29 under increased CST condition, thereby forcing the line to produce only sterile pollen.

Table 2. Gas Exchange Parameters and Hill Reaction In Ts 29 And Co 46

\begin{tabular}{|c|c|c|c|c|}
\hline Treatments & $\begin{array}{c}\text { Photosynthetic rate }(\mathrm{Pn})(\mu \\
\left.\mathrm{mol} \mathrm{CO} 2 \mathrm{~m}^{-2} \mathrm{~s}^{-1}\right)\end{array}$ & $\begin{array}{c}\text { Transpiration rate }(\mathrm{E})(\mathrm{m} \\
\left.\mathrm{mol} \mathrm{H} 2 \mathrm{O} \mathrm{m}^{-2} \mathrm{~s}^{-1}\right)\end{array}$ & $\begin{array}{c}\text { Diffusive resistance } \\
(\mathrm{rs})\left(\mathrm{s} \mathrm{cm}^{-1}\right)\end{array}$ & $\begin{array}{c}\text { Hill reaction rate }(\mu \\
\text { moles DCIP reduced } \mathrm{mg}^{-1} \\
\left.\text { chlorophyll } \mathrm{hr}^{-1}\right)\end{array}$ \\
\hline $\begin{array}{c}\text { TS 29 Glass house } \\
\text { (Fertile pollen) }\end{array}$ & $20.50 \pm 1.02(100.0)$ & $7.50 \pm 0.62(100.0)$ & $5.60 \pm 0.19(100.0)$ & $39.68 \pm 1.05(100.0)$ \\
\hline $\begin{array}{c}\text { TS 29 Phytotron (Sterile } \\
\text { pollen) }\end{array}$ & $13.10 \pm 0.28(63.9)$ & $7.00 \pm 0.44(93.3)$ & $6.49 \pm 0.25(114.3)$ & $27.41 \pm 0.77(69.1)$ \\
\hline CO 46 Glass house & $22.50 \pm 0.95(100.0)$ & $7.70 \pm 0.58(100.0)$ & $5.20 \pm 0.22(100.0)$ & $41.30 \pm 1.54(100.0)$ \\
\hline CO 46 Phytotron & $20.16 \pm 0.86(89.6)$ & $7.50 \pm 0.62(97.4)$ & $5.40 \pm 0.18(103.9)$ & $40.96 \pm 1.48(99.2)$ \\
\hline Mean & 19.07 & 7.43 & 5.65 & 37.34 \\
\hline CD (P=0.05) & 0.377 & 0.262 & 0.231 & 0.793 \\
\hline
\end{tabular}

(Values in parentheses are per cent change in Phytotron plants as compared to glass house plants. Values from glass house plants were set as $100 \%$ )

Table 3. Carbohydrate Fractions in Leaves Of Ts 29 And Co 46

\begin{tabular}{|c|c|c|c|c|c|c|c|c|}
\hline Treatments & \multicolumn{2}{|c|}{ Reducing sugars ( $\left.\mathrm{mg} \mathrm{g}^{-1}\right)$} & \multicolumn{2}{|c|}{ Total sugars $\left(\mathrm{mg} \mathrm{g}^{-1}\right)$} & \multicolumn{2}{|c|}{ Starch content (mg g ${ }^{-1}$ ) } & \multicolumn{2}{|c|}{$\begin{array}{l}\text { Total carbohydrates (mg } \\
\left.\mathrm{g}^{-1}\right)\end{array}$} \\
\hline $\begin{array}{l}\text { TS } 29 \text { Glass house (Fertile } \\
\text { pollen) }\end{array}$ & $7.52 \pm 0.81$ & $(100.0)$ & $24.29 \pm 1.04$ & $(100.0)$ & $37.14 \pm 1.52$ & $(100.0)$ & $77.91 \pm 2.04$ & $(100.0)$ \\
\hline $\begin{array}{c}\text { TS } 29 \text { Phytotron (Sterile } \\
\text { pollen) }\end{array}$ & $5.61 \pm 0.63$ & $(74.6)$ & $16.93 \pm 0.88$ & $(69.7)$ & $51.26 \pm 1.83$ & $(138.0)$ & $65.43 \pm 1.98$ & $(83.9)$ \\
\hline CO 46 Glass house & $7.43 \pm 0.74$ & $(100.0)$ & $24.71 \pm 1.02$ & $(100.0)$ & $34.32 \pm 1.66$ & $(100.0)$ & $85.39 \pm 2.55$ & $(100.0)$ \\
\hline CO 46 Phytotron & $7.34 \pm 0.82$ & $(98.7)$ & $23.21 \pm 1.00$ & $(93.9)$ & $33.98 \pm 1.72$ & $(99.0)$ & $84.65 \pm 2.48$ & $(99.1)$ \\
\hline Mean & 6.98 & & 22.29 & & 39.18 & & 78.35 & \\
\hline $\mathrm{CD}(\mathrm{P}=0.05)$ & 0.248 & & 2.069 & & 0.967 & & 0.545 & \\
\hline
\end{tabular}

(Values in parentheses are per cent change in Phytotron plants as compared to glass house plants. Values from glass house plants were set as $100 \%$ ) 


\section{REFERENCES}

[1] Khush, G.S. 2000. New plant type of rice for increasing the genetic yield potential. In: Rice Breeding and Genetics: Research Priorities and Challenges. Nanda, J.S. (ed.). Oxford and IBP Publishing Co., New Delhi.

[2] Bose, A. and Ghosh,B.1995. Response of photosynthetic apparatus in rice cultivars under heat stress. Photosynthetica, 31(4): $625-630$

[3] Tang, C.Q.; Tong,Z.; Peng, D.C. and Q.D.Zhang. 1994. Photosynthetic characteristics of chloroplasts in photoperiod sensitive genic male sterile rice (Nongken $58 \mathrm{~S}$ rice). Acta Phytophysiol. Sin., 20(3): 257-262.

[4] Fleischhacker, P. and Senger, H. 1978. Adaptation of the photosynthetic apparatus of Scenedesmus obliguus to strong and weak light conditions. II. Differences in photochemical reactions, the photosynthetic electron transport and photosynthetic unit. Physiol. Plant., 43: 43-51.

[5] Somogyi, M. 1952. Notes on sugar determination. J. Biol. Chem., 200: 245-247.

[6] Hedge, J.E. and B.T.Hofreiter. 1962. In: Carbohydrate Chemistry. Whistler, R.L. and J.N.Be Miller (eds.). Academic Press, New York.

[7] Vani, B., Saradhi, P.P. and Prasanna Mohanty. 2001. Characterization of high temperature induced stress impairments in thylakoids of rice seedlings. Indian $J$. Biochem. Biophys., 38(4): 220-229.
[8] Maruyama, S., Yatomi, M and Nakamura, Y. 1990. Response of rice leaves to low temperature. I. Changes in basic biochemical parameters. Plant Cell Physiol., 31(3): 303-309.

[9] Roystephen. 1998. Physiological and biochemical mechanisms of thermosensitive genic male sterility (TGMS) in rice (Oryza sativa L.). Ph.D. Thesis, TNAU, Coimbatore.

[10] Tanner, C.B. 1963. Plant temperatures. Agron. J., 55: 210-211.

[11] Morrow, P.A. and.Slatyer. R.O. 1971. Leaf temperature effects on measurements of diffusion resistance to water vapor transfer. Plant Physiol. 47: 559-561

[12] Ma Dehua; Pang Jinan and Huo Zhennong. 1999. Study on the resistance of cucumber to temperature stresses. Chinese Agric. Sci., 22(2): 80-89.

[13] Markova, M. and S.Daskaloff. 1976. Biochemical investigations of male sterile mutant forms of pepper. $\mathrm{Z}$. Pflanzenzucht, 77: 296-303.

[14] Chauhan, S.V.S. and Kinoshita. T. 1980. Cytohistological and biochemical studies on pollen abortion in Datura alba $\mathrm{L}$. plants treated with gametocidal compounds. Proc. Japan Acad. Sci., 56: 344-349.

[15] Peng, Y.F. and Wang. Y.R. 1991. Studies on starch and protein content of HPGMR during pollen abortion. Acta Sci. Natur. Univ. Sunyatseni, 30(4): 92-99.

[16] Lakshmi Praba and Thangaraj (2000). Critical stage of thermosensitivity and critical sterility temperature in TGMS lines of rice. TNAU Newsl., 29(5): 4. 